\title{
Multimodal deep learning enhances diagnostic precision in left ventricular hypertrophy
}

Jessica Torres Soto ${ }^{1}$, J. Weston Hughes ${ }^{2}$, Pablo Amador Sanchez ${ }^{3}$, Marco Perez ${ }^{3}$, David Ouyang $^{4,5}$, Euan Ashley ${ }^{3}$

1. Department of Biomedical Data Science, Stanford University

2. Department of Computer Science, Stanford University

3. Department of Medicine, Division of Cardiology, Stanford University

4. Department of Cardiology, Smidt Heart Institute, Cedars-Sinai Medical Center

5. Division of Artificial Intelligence in Medicine, Department of Medicine, Cedars-Sinai Medical Center

13 Correspondence: euan@stanford.edu

\section{Abstract}

15 Determining the etiology of left ventricular hypertrophy $(\mathrm{LVH})$ can be challenging due to the

16 similarity in clinical presentation and cardiac morphological features of diverse causes of

17 disease. In particular, distinguishing individuals with hypertrophic cardiomyopathy (HCM) from

18 the much larger set of individuals with manifest or occult hypertension (HTN) is of major

19 importance for family screening and the prevention of sudden death. We hypothesized that deep

20 learning based joint interpretation of 12 lead electrocardiograms and echocardiogram videos

21 could augment physician interpretation. We chose not to train on proximate data labels such as

22 physician over-reads of ECGs or echocardiograms but instead took advantage of electronic

23 health record derived clinical blood pressure measurements and diagnostic consensus (often

24 including molecular testing) among physicians in an HCM center of excellence. Using over

2518,000 combined instances of electrocardiograms and echocardiograms from 2,728 patients, we

26 developed LVH-Fusion. On held-out test data, LVH-Fusion achieved an F1-score of 0.71 in

27 predicting HCM, and 0.96 in predicting HTN. In head-to-head comparison with human readers

28 LVH-Fusion had higher sensitivity and specificity rates than its human counterparts. Finally, we

29 use explainability techniques to investigate local and global features that positively and

30 negatively impact LVH-Fusion prediction estimates providing confirmation from unsupervised

NOTE: This preprint reports new research that has not been certified by peer review and should not be used to guide clinical practice. 
31 analysis the diagnostic power of lateral T wave inversion on the ECG and proximal septal

32 hypertrophy on the echocardiogram for HCM. In conclusion, these results show that deep

33 learning can provide effective physician augmentation in the face of a common diagnostic

34 dilemma with far reaching implications for the prevention of sudden cardiac death.

\section{Introduction}

38 Hypertrophic cardiomyopathy (HCM) is the most common cardiac genetic disease with an

39 estimated prevalence in the general population of 1:500 to 1:200. ${ }^{1} \mathrm{HCM}$ is an autosomal

40 dominant mendelian disease that can be associated with significant morbidity in the form of heart

41 failure and sudden death. ${ }^{2}$ Thus, identifying patients with HCM has significance well beyond the

42 individual, with many proband diagnoses leading to screening of several generations of a family.

43 Diagnosis of HCM can be difficult due to the high prevalence of manifest hypertension in the

44 general population, present in up to $45 \%$ of US adults ${ }^{3}$ (this before counting the occult disease).

45 Thus, a common diagnostic dilemma for clinicians when faced with LVH on the ECG or

46 echocardiogram is how to rule out HCM. In a small study, the rates of misclassification of HCM

47 were as high as $30 \%$ percent with hypertension being the most common misdiagnosis ${ }^{4}$. Although

48 the American Heart Association provides guidelines for the diagnosis of hypertension and HCM

49 separately, distinguishing between them is a task that most physicians feel ill equipped to

50 perform (understandably as HCM is a rare disease not commonly encountered even in general

51 cardiology practice). This provides an opportunity for physician augmentation through artificial

52 intelligence (AI).

54 New advances in artificial intelligence have led to rapid expansion of medical deep learning

55 applications with an emphasis on medical specialties that hold a high degree of visual pattern

56 recognition tasks like radiology, pathology, ophthalmology, dermatology and most notably

57 cardiology. ${ }^{5}$ Imaging and electrical phenotypes of hypertrophic cardiomyopathy ${ }^{6,7}$ are the first

58 line clinical tools. 
60 Interpretation of the ECG relies on direct visual assessment making it ideal for deep learning

61 approaches. Previous work has demonstrated that demographic and medical data can be learned

62 including detection of low ejection fraction, something typically requiring echocardiography to

63 confirm ${ }^{8-11}$. Our prior work using video computation of echocardiograms has demonstrated

64 efficient detection of left ventricular hypertrophy and the identification of a broad range of

65 cardiovascular disease. ${ }^{12,13}$

67 Combining data sources as human diagnosticians do, has the potential to provide an artificial 68 intelligence (AI) algorithm with greater diagnostic power ${ }^{14}$. We focus here on the two most

69 frequent diagnostic modalities in cardiology. To date, no published work has explored the

70 benefits of a multimodal deep learning model using electrocardiogram and echocardiogram data,

71 although there has been some exploration of combining separately trained diagnostic models in a

72 single pipeline ${ }^{15}$. We hypothesize that multimodal deep learning may provide added benefit in

73 distinguishing patterns that are not easily discernible from individual modalities. We present

74 LVH-fusion, the first model to jointly model electrical and ultrasound-based time series data of

75 the heart. We demonstrate its potential with application to the diagnosis of left ventricular

76 hypertrophy.

\section{Results}

78 We developed a multi-modal deep learning framework, LVH-fusion, that takes as input time based

79 electrical and echocardiographic data of the heart. We applied this framework in a common clinical

80 challenge: the determination of the etiology of left ventricular hypertrophy. Motivated by prior work on

81 deep learning applied to electrocardiogram signals and echocardiogram videos ${ }^{9,13,16}$, LVH-fusion jointly

82 models both electrocardiogram and echocardiogram data. It is trained not with proximate human derived

83 ECG and echocardiogram labels but rather via a gold standard diagnosis independently derived from the

84 Electronic Health Records (HTN) or through the consensus diagnosis of HCM within a center of

85 excellence.

86 In this study, both single-modal and multimodal neural network models were examined (Figure 1). Four

87 different multimodal fusion architectures were explored, combining ECG and echocardiogram

88 information in different ways. For both late-average fusion and late-ranked fusion models, decision level 
medRxiv preprint doi: https://doi.org/10.1101/2021.06.13.21258860; this version posted June 15, 2021. The copyright holder for this preprint (which was not certified by peer review) is the author/funder, who has granted medRxiv a license to display the preprint in perpetuity.

All rights reserved. No reuse allowed without permission.

fusion was used to combine the outputs of electrocardiogram and echocardiogram classifiers ${ }^{17}$. In the lateaverage fusion model, soft voting is performed by computing the average probability for each class from the individual ECG and echocardiogram classifiers and predicts the class with maximal average

92 probability. In the late-ranked fusion model, the probabilities for each class from the individual ECG and

93 echocardiogram classifiers are ranked and a prediction is determined from the highest ranked probability.

94 For the late fusion models, both pre-trained and random, the learned feature representations from each

95 modality were concatenated together before the final classification layer. In this situation the fusion

96 model considers both inputs and during training and the loss is calculated jointly. We explored the

97 benefits of randomly initialized weights and pretrained weights in the late fusion model. Lastly, the single

98 modal models provide a benchmark against which to compare multimodal models that jointly consider the

99 paired electrocardiogram and echocardiogram data, demonstrating the benefit of a combined approach.

\section{Data Acquisition and selection}

101 With the approval of Stanford Institutional Review Board (IRB), we retrieved electrocardiograms and 102 echocardiograms from patients between 2006 and 2018 at Stanford Medicine (Table 1). The data was split 103 into training, validation, and test sets with no patient overlap between sets. Due to the fact that multiple 104 electrocardiograms and echocardiograms are present within the healthcare system record, we explored 105 various data selection scenarios to understand what selection methods are best suited for this specific task. 106 The quantitative comparison of all data selection used can be found in Supplementary Table S1. The final 107 model was trained using a patient's first ECG and first echocardiogram in the system.

\section{Model performance}

109 Four multimodal fusion models were explored: late-average, late-ranked, pre-trained late fusion 110 and random late fusion (Figure 1). The performance metrics of each model is detailed in Table 2.

111 The late average model achieved the highest F1-score and specificity rates $0.711(0.571-0.826)$

112 and $0.952(0.921-0.979)$ respectively on the held-out test set. We conducted experiments to

113 study the performance of single-modal models trained on only ECG and echo to demonstrate the

114 benefit of multimodal models. The multimodal models outperform single-modal model F1-

115 scores, which increase from 0.63 to 0.71 . Furthermore, the false-discovery rates are significantly

116 reduced from 0.45 to 0.3 . To provide context for these results, we also trained the single-modal

117 models to predict left ventricular etiology using standard quantitative features from the

118 electrocardiogram. This baseline model achieved sensitivity rates of 0.51 for predicting HCM

119 which is considerably lower than LVH-Fusion (Supplementary Table S2). These results show 
medRxiv preprint doi: https://doi.org/10.1101/2021.06.13.21258860; this version posted June 15, 2021. The copyright holder for this preprint (which was not certified by peer review) is the author/funder, who has granted medRxiv a license to display the preprint in perpetuity.

All rights reserved. No reuse allowed without permission.

120 that the proposed electrocardiogram signals model discover novel characteristics not accounted

121 for with the quantitative features. Lastly, to examine the discriminatory power of our

122 methodology, we performed a sensitivity analysis for predicting LVH etiology including the

123 additional classification task of "normal." In this context, LVH-fusion maintains high

124 discriminatory power in predicting LVH from normal ECG and echocardiogram videos,

125 suggesting that false positive rates of hypertension or hypertrophic cardiomyopathy would be

126 low if the model was extended to this use case (Supplementary Table S3 and S4).

128 Understanding model performance

129 In order to improve our understanding of how LVH-Fusion classifies left ventricular etiology, we

130 implemented a series of ablation studies similar to Hughes et al. $2021^{18}$ to determine what

131 information models rely on to make predictions. For electrocardiogram single-modal models we

132 examined the impact of varying the number of leads from the standard 12 leads to 8 leads and

133 masking each lead to understand the impact each lead holds for prediction estimates. We find

134 that although no single lead harbors a statistically significant impact on the overall model

135 performance, masking out lead V3 and aVR had the highest negative impact on prediction

136 estimates, Figure 2. Next, since the standard 12 lead ECG contains 8 algebraically independent

137 leads, we considered the impact of masking multiple leads combinations. We observe an overall

138 reduction in classification metrics when masking multiple leads at a time with no significant

139 difference between masking the 4 dependent leads (III, aVL, aVF, aVR) and a random

140 subselection of 4 leads, Supplementary Figure S2. These results suggest our model benefits from

141 the complete 12 lead input and classification metrics are negatively impacted with any

142 nonspecific reduction in leads.

144 For the echocardiogram single-modal model, we examined segmentation, restricting the

145 prediction algorithm to i) only the region around the left ventricle, ii) random single frames, and 146 iii) single end diastolic frames. Restricting the echocardiogram model to the area around the left

147 ventricle caused a decrease in accuracy, showing the model relies on information outside of that

148 region to make classifications. This is interesting given the focus of clinicians on the left

149 ventricle when considering $\mathrm{LVH}$, even despite the fact that hypertension could impact the left 
medRxiv preprint doi: https://doi.org/10.1101/2021.06.13.21258860; this version posted June 15, 2021. The copyright holder for this preprint (which was not certified by peer review) is the author/funder, who has granted medRxiv a license to display the preprint in perpetuity.

All rights reserved. No reuse allowed without permission.

150 atrium by causing restriction and HCM affects all four chambers. Restricting the model's input

151 to a single frame further decreases accuracy, demonstrating that motion information is important

152 in distinguishing between HCM and hypertension. Figure 2 details the performance of each

153 ablation experiment.

155 Model interpretations

156 In order to improve our understanding of how LVH-Fusion classifies left ventricular etiology, we

157 implemented SHAP GradientExplainer, a game theory approach to explain the output of a

158 machine learning algorithm ${ }^{19}$. Relating this method to the ECG model, this approach takes the

159 prediction of a model and estimates the gradient with respect to each individual timestep for

160 every lead from the input signal. For echocardiogram videos, an analogous methodology applies:

161 the gradient of the model's prediction was calculated with respect to every pixel from the input

162 video. In each case, the calculated value is then compared to a provided background distribution,

163 the training data. The value of the calculated gradients for each timestep/pixel is then assigned an

164 importance score such that highly impactful scores (denoted in red) hold positive impacts on

165 prediction estimates. Values with low importance scores negatively influence prediction

166 estimates (denoted in blue).

168 We emphasize samples of ECG and echocardiograms from the test partition to deduce regions

169 the model found most impactful to prediction estimates, Figure 3 and 4. In Figure 3, the ECG

170 interpretation results highlight an overall focus on V3 and T-wave inversion in leads V1-V6.

171 Both the observed early $\mathrm{R}$ wave progression and T-wave inversion are indications of HCM.

172 Summarized local interpretations for each lead provides explanations of the overall impact each

173 lead has on prediction estimates. Additional examples of ECG interpretation tracings can be

174 found in the Supplement Figure S1. Comparably, the interpretation results of the echocardiogram

175 videos, Figure 4, clearly depicts asymmetric proximal septal thickness, a hallmark distinction of

176 HCM across all frames of the video. Next, to examine local summary interpretations, we

177 segmented the left ventricle on each frame for duration of a video's length. This allowed us to

178 quantitatively compare the positive and negative impacts the estimated LV size had on overall

179 prediction estimates, Supplemental Figure S3. 
medRxiv preprint doi: https://doi.org/10.1101/2021.06.13.21258860; this version posted June 15, 2021. The copyright holder for this preprint (which was not certified by peer review) is the author/funder, who has granted medRxiv a license to display the preprint in perpetuity.

181 To further examine if the regions of importance identified in distinct samples are globally similar

182 across all predictions, a summation or averaging across all local instances was performed. This

183 approach provides a highly compressed, global insight into the model's behavior. We considered

184 per lead contributions to predictions in ECGs and left ventricular segmentation in

185 echocardiogram videos. Global summary results for ECG corroborates our results from the

186 ablation studies, lead V3 and aVR holds valuable information for model's prediction estimates,

187 Supplement Figure S4.

188 Comparison against physician interpretation

189 We had two expert readers review ECG tracings and echocardiogram videos and asked them to 190 make a diagnosis of HTN or HCM. We selected 45 samples (40 HTN and 5 HCM) from the test

191 set to compare LVH-fusion. The LVH-fusion model outperformed these expert cardiologists

192 (one of whom has 20 years of experience in diagnosing HCM). LVH-fusion correctly classified 3

193 out of the 5 ECG and echocardiogram HCM samples. Variability between cardiologists varied

194 greatly, with one cardiologist matching LVH-fusion sensitivity estimates but with a reduction in

195 specificity, while cardiologist two failed to correctly classify any of the HCM ECG samples

196 provided.

\section{Discussion}

198 In this study, we report the first multimodal (ECG and echocardiogram based) deep learning

199 model in clinical cardiology and use it to predict the etiology of left ventricular hypertrophy.

200 Combining complementary knowledge from multiple modalities can improve diagnostic

201 performance in clinical practice. The trained model demonstrates high discriminatory ability in

202 distinguishing hypertrophic cardiomyopathy from hypertension with an AUC of 0.91, AUPRC of

203 0.78. Furthermore, ablation studies provided independent support from unsupervised analysis for

204 clinicians' focus on ECG lateral repolarization and echocardiographic proximal septal

205 hypertrophy for the diagnosis of HCM. Combining complementary information from multiple

206 modalities is intuitively appealing for improving the performance of learning-based approaches.

207 Our results can be directly applied in general medical and cardiology clinics where exposure to

208 rare conditions such as HCM limits confidence in human diagnostic prediction alone. 
210 Deep learning models specifically focused on single modalities in cardiology have shown

211 impressive results for arrhythmia detection, age, and other clinical actionable insights ${ }^{8,10,16}$.

212 Previously Ko et al., focused on using convolutional neural networks (CNN) for ECG

213 interpretation with respect to $\mathrm{HCM}^{22}$. They showed high discriminatory power in classifying

214 HCM against a background population of left ventricular hypertrophy by ECG alone. However,

215 approximately 28-30\% of HCM cases had concurrent hypertension, inhibiting a direct

216 comparison of possible distinction between HCM and hypertension. To date, deep learning

217 research addressing non-pulmonary hypertension detection using electrocardiogram or

218 echocardiogram was unknown. One previous approach successfully used both ECG and

219 echocardiogram data individually with a stepwise approach to diagnosis of cardiac

220 amyloidosis $^{15}$, whereas here we focus on fusion method applications of multi-modal deep

221 learning of electrocardiograms and echocardiograms together.

223 Medical decision making is complex, often relying on a combination of physician's judgment,

224 experience, diagnostic and screening test results, and longitudinal follow-up. In the case of a

225 patient presenting with anything other than severe, grossly asymmetric LVH, suspicion for HCM

226 would be higher for patients who do not obviously have hypertension. However, occult

227 hypertension is common and challenging to rule out and with mild "gray zone" hypertrophy, it is

228 not uncommon to make this assumption. Similarly, for patients who present with LVH and

229 manifest hypertension, the question is always "is hypertension alone enough to explain this

230 degree of LVH?" Given the implications of missing a diagnosis of HCM-a mendelian disease

231 associated with heart failure and sudden death-most generalists do not feel confident ignoring

232 the possibility of HCM. In these cases, aggressively treating hypertension and re-reviewing the

233 patient can help but challenges in follow up, adherence, and effectiveness of therapy make the

234 window of equipoise long. These are the clinical scenarios into which LVH-fusion will have the

235 most benefit. Yet, this is merely the first application of the approach. A similar approach to the

236 identification of other causes of LVH such as Fabry disease or cardiac amyloidosis can be

237 applied using similar "gold standard" diagnostic labels to those we use here. The future of deep

238 learning in medicine is a move beyond reproducing human derived label features to capitalizing 
medRxiv preprint doi: https://doi.org/10.1101/2021.06.13.21258860; this version posted June 15, 2021. The copyright holder for this preprint (which was not certified by peer review) is the author/funder, who has granted medRxiv a license to display the preprint in perpetuity.

All rights reserved. No reuse allowed without permission.

on unsupervised machine learned features vs a gold standard diagnostic or prognostic label. This will allow machine augmentation of the human led diagnostic journey.

242 In summary, we develop a deep learning model incorporating ECG and echocardiogram time

243 series data and apply it to help identify hypertrophic cardiomyopathy patients from within the

244 much larger group of patients presenting with LVH due to hypertension or unknown causes. We

245 present various well known fusion methods of combining data streams from multiple modalities

246 and compare these comprehensively to single-modal models. Further studies should explore the

247 real-world application of physician augmentation approaches like LVH-fusion in medical

248 practice.

249 Methods

250 Data acquisition and study population

251 Hypertrophic cardiomyopathy patients were selected for this study from the Hypertrophic

252 Cardiomyopathy clinics at the Stanford Center for Inherited Cardiovascular Disease.

253 Hypertension patients were selected from individuals that were found to be persistently

254 hypertensive (SBP > 150) with at least 5 consecutive systolic blood pressure readings over 150.

255 Exclusion criteria included any ECG clinical annotations of ventricular-pacing or left bundle

256 branch block. In addition, we excluded any data from both electrocardiograms and

257 echocardiograms datasets if the date acquired was after a documented myectomy procedure.

259 We retrieved 15,761 electrocardiograms (ECGs) and 3,234 transthoracic echocardiograms from

260 2,728 unique individuals at Stanford Health Care, Table 1. Standard 12 lead ECGs were divided

261 into training, validation, and test partitions based on a unique patient identification number to

262 ensure that no patient overlap existed across data partitions. Echocardiogram videos from

263 Stanford Medicine were curated for apical 4-chamber view videos.

264 Data Processing and selection

265 Electrocardiogram signals were filtered to remove any baseline wander and powerline

266 interference. Normalization of 12 lead ECGs was performed by lead over a random subset of the 
267 study sample population, using mean and standard deviation. Echocardiogram videos were

268 processed in an identical method as Oyuang et $\mathrm{al}^{13}$. Given multiple electrocardiograms and echocardiograms per individual present within our dataset, we examined the effects of different

270 data selection methods on model training and performance metrics. We selected three different

271 data selection methods: 1) first clinical presentation for all data partitions, 2) all clinical

272 presentations in the training partition with only first clinical presentation selected for the

273 validation and test partitions, and 3) all clinical presentations for all partitions. Extended details

274 of each selection method can be found in Supplemental Table 1.

\section{Overview of model training framework}

276 Training for the single-modal and multimodal neural network models were executed

277 independently.

278 Models were trained using a two-stage grid search approach to find the optimal hyperparameters.

279 In the initial hyperparameter search, evaluation metrics from the validation set can be found in

280 the Supplementary Tables S5, S6. The hyperparameters that yielded the best performing models

281 were selected for additional training and hyperparameter search considering various loss

282 functions, loss weighting for minority class and minority class oversampling. Final models were

283 selected from the lowest validation loss.

284 Single-modal model training

285 For electrocardiogram single-modal model training, the following hyperparameters included:

286 model architecture: \{VGG11, VGG13, VGG16, VGG19, densenet169, densenet121,

287 densenet201, densenet161 resnet18, resnet34, resnet50, resnet101, resnet152, resnext50_32x4d,

288 resnext101_32x8d, wide_resnet50_2 wide_resnet101_2\}; batch size: $\{32,64,75\}$; Optimizer:

$289\{$ SGD, adam $\}$, and Hz: $\{500,250\}$. The first hyperparameter search involved training all

290 combinations of hyperparameters above for 100 epochs and saving results from the epoch with

291 the lowest loss. Furthermore, we explored a second hyperparameter search which explored class

292 weighted loss functions, oversampling minority class samples and setting final bias term to the

293 expected class ratios from top performing models from the initial hyperparameters search. We

294 examined expanding training to 150 epochs and considering both loss and auPRC results for

295 selection of the final model. The selected hyperparameters that resulted in best performance on 
medRxiv preprint doi: https://doi.org/10.1101/2021.06.13.21258860; this version posted June 15, 2021. The copyright holder for this preprint (which was not certified by peer review) is the author/funder, who has granted medRxiv a license to display the preprint in perpetuity.

All rights reserved. No reuse allowed without permission.

296 the validation set were the following: resnet 34 model, oversampling minority class, adam optimizer,

297 batch size of 64 , and sampling rate of 500.

299 For echocardiogram unimodal model training, the following hyperparameters included: Model

300 architecture: $\{$ r2plus1d_18, mc3_18, r3d_18\}, Number of frames: $\{96,64,32,16,8,4,1\}$;

301 Period: $\{2,4\}$; Pretrained weights: $\{$ True, False $\}$. The first hyperparameter search involved

302 training all combinations of hyperparameters above for 100 epochs and saving results from the

303 epoch with the lowest loss. Furthermore, we explored a second hyperparameter search which

304 explored class weighted loss functions, oversampling minority class samples and setting final

305 bias term to the expected class ratios from top performing models from the initial

306 hyperparameters search. We examined expanding training to 300 epochs and considering both

307 loss and auPRC results for selection of the final model. The selected hyperparameters that

308 resulted in best performance on the validation set were the following: r2plus1d_18 model,

309 pretrained weights, weighted minority class, adam optimizer, batch size of 20, and frames 16 with sampling

310 period of 4.

\section{Multimodal model training}

312 For multimodal training models, the electrocardiogram and echocardiogram data were paired

313 according to unique patient identifiers. Data selection for the earliest clinical encounter was

314 selected for all training, validation and test set partitions; this resulted in a total of 1,414 training,

315176 validation, and 168 internal test samples. The detailed characteristics of the dataset can be

316 found in Table 1. We hypothesized that using the learned weights from the single-modal models

317 would benefit training so we explored both pre-trained late fusion and random late fusion

318 models. All multimodal models were trained to 300 epochs and we considered both loss and

319 auPRC results for selection of the final multimodal model. We implemented LVH-Fusion using

320 PyTorch on the Stanford University Research cluster, Sherlock. The selected hyperparameters

321 that resulted in best performance on the validation set were the following: r2plus1d_18 model +

322 resnet 34, pretrained weights, weighted minority class, adam optimizer, batch size of 10, and

323 frames 16 with sampling period of 4. 
medRxiv preprint doi: https://doi.org/10.1101/2021.06.13.21258860; this version posted June 15, 2021. The copyright holder for this preprint (which was not certified by peer review) is the author/funder, who has granted medRxiv a license to display the preprint in perpetuity.

All rights reserved. No reuse allowed without permission.

325 Standard reported features from Tracemaster electrocardiogram machines were extracted for 326 each ECG considered in this study. We used these features for input into a XGboost model to

327 determine if a feature-based method would exceed the performance metrics of the unimodal

328 neural network models. The list of ECG features used were modeled from Kwon et al. $2020{ }^{10}$.

329 Comparison with normal samples

330 In order to explore how our neural networks, perform on non-left ventricular hypertrophy

331 individuals, we sampled electrocardiograms with clinical annotations of sinus rhythm and

332 echocardiograms with a normal ejection fraction greater than 45 . We took the best performing

333 single-modal model and retrained them to include an additional non-LVH class; details of

334 sample size and performance metrics can be found in Supplementary Table 5 and Supplementary

335 Table 6, respectively.

336 Ablation experiments

337 To further understand how the neural networks make their predictions, we explored various 338 ablation studies.

339 We retrained the single-modal echo model with data ablated in the following ways:

1) a single randomly selected frame of each echo, repeated for the length of the original video to compare to the best performing unimodal model.

347 For electrocardiogram we retrained the single-modal models for the following experiments:

348 1) Using 8 of the 12 leads, to compare to the best performing unimodal model.

2) Masking out each lead independently to compare to the best performing single-modal

351 Echocardiogram models were trained to 300 epochs and electrocardiogram models were trained 352 for 150 epochs. 
medRxiv preprint doi: https://doi.org/10.1101/2021.06.13.21258860; this version posted June 15, 2021. The copyright holder for this preprint (which was not certified by peer review) is the author/funder, who has granted medRxiv a license to display the preprint in perpetuity.

354 SHAP GradientExplainer ${ }^{19}$ uses an extension of integrated gradient values and SHAP values,

355 which aims to attribute an importance value to each input feature by integrating the gradients of

356 all interpolations between a foreground sample (test samples) and a provided background

357 samples (training data). The importance scores sum up to approximately the difference between

358 the expected value of all background samples and the individual prediction estimate of interest.

359 We applied this method to both ECG and echocardiogram models; 1500 samples were used to

360 build the background distribution for the ECG model and 80 samples were used to build the

361 background distribution for the echocardiogram model. In both cases, the full test set was used as

362 foreground samples.

\section{Data and Code availability}

365 All the code for LVH-Fusion will be available at https://github.com/AshleyLab/lvh-fusion/ after

366 publication. The data that support the findings of this study are available on request from the 367 corresponding author upon approval of data sharing committees of the respective institutions.

\section{References}

371 1. Semsarian, C., Ingles, J., Maron, M. S. \& Maron, B. J. New perspectives on the prevalence

372 of hypertrophic cardiomyopathy. J. Am. Coll. Cardiol. 65, 1249-1254 (2015).

373 2. Ho, C. Y. et al. Genotype and Lifetime Burden of Disease in Hypertrophic Cardiomyopathy:

374 Insights from the Sarcomeric Human Cardiomyopathy Registry (SHaRe). Circulation 138,

$375 \quad$ 1387-1398 (2018).

376 3. Whelton, P. K. et al. 2017 
medRxiv preprint doi: https://doi.org/10.1101/2021.06.13.21258860; this version posted June 15, 2021. The copyright holder for this preprint (which was not certified by peer review) is the author/funder, who has granted medRxiv a license to display the preprint in perpetuity.

All rights reserved. No reuse allowed without permission.

Prevention, Detection, Evaluation, and Management of High Blood Pressure in Adults: A

Report of the American College of Cardiology/American Heart Association Task Force on Clinical Practice Guidelines. Hypertension 71, e13-e115 (2018).

4. Magnusson, P., Palm, A., Branden, E. \& Mörner, S. Misclassification of hypertrophic cardiomyopathy: validation of diagnostic codes. Clin. Epidemiol. 9, 403-410 (2017).

5. Esteva, A. et al. Deep learning-enabled medical computer vision. NPJ Digit Med 4, 5 (2021).

6. Pennacchini, E., Musumeci, M. B., Fierro, S., Francia, P. \& Autore, C. Distinguishing hypertension from hypertrophic cardiomyopathy as a cause of left ventricular hypertrophy. J. Clin. Hypertens. 17, 239-241 (2015).

7. Doi, Y. L. et al. Echocardiographic differentiation of hypertensive heart disease and hypertrophic cardiomyopathy. Br. Heart J. 44, 395-400 (1980).

8. Attia, Z. I. et al. Age and Sex Estimation Using Artificial Intelligence From Standard 12Lead ECGs. Circ. Arrhythm. Electrophysiol. 12, e007284 (2019).

9. Hannun, A. Y. et al. Cardiologist-level arrhythmia detection and classification in ambulatory electrocardiograms using a deep neural network. Nat. Med. 25, 65-69 (2019).

394 10. Kwon, J.-M. et al. A deep learning algorithm to detect anaemia with ECGs: a retrospective, 395 multicentre study. Lancet Digit Health 2, e358-e367 (2020).

396 11. Yao, X. et al. Artificial intelligence-enabled electrocardiograms for identification of patients with low ejection fraction: a pragmatic, randomized clinical trial. Nature Medicine (2021) doi:10.1038/s41591-021-01335-4.

12. Madani, A., Ong, J. R., Tibrewal, A. \& Mofrad, M. R. K. Deep echocardiography: data400 efficient supervised and semi-supervised deep learning towards automated diagnosis of 
medRxiv preprint doi: https://doi.org/10.1101/2021.06.13.21258860; this version posted June 15, 2021. The copyright holder for this preprint (which was not certified by peer review) is the author/funder, who has granted medRxiv a license to display the preprint in perpetuity.

cardiac disease. NPJ Digit Med 1, 59 (2018).

402 13. Ouyang, D. et al. Video-based AI for beat-to-beat assessment of cardiac function. Nature 580, 252-256 (2020).

404 14. Huang, S.-C., Pareek, A., Zamanian, R., Banerjee, I. \& Lungren, M. P. Multimodal fusion with deep neural networks for leveraging CT imaging and electronic health record: a casestudy in pulmonary embolism detection. Sci. Rep. 10, 22147 (2020).

407 15. Goto, S. et al. Artificial intelligence-enabled fully automated detection of cardiac amyloidosis using electrocardiograms and echocardiograms. Nat. Commun. 12, 2726 (2021).

409 16. Attia, Z. I. et al. An artificial intelligence-enabled ECG algorithm for the identification of 410 patients with atrial fibrillation during sinus rhythm: a retrospective analysis of outcome $411 \quad$ prediction. Lancet 394, 861-867 (2019).

412 17. Sagi, O. \& Rokach, L. Ensemble learning: A survey. Wiley Interdiscip. Rev. Data Min. $413 \quad$ Knowl. Discov. 8, e1249 (2018).

414 18. Hughes, J. W. et al. Deep learning prediction of biomarkers from echocardiogram videos. bioRxiv (2021) doi:10.1101/2021.02.03.21251080.

416 19. Sundararajan, M., Taly, A. \& Yan, Q. Axiomatic attribution for deep networks. arXiv $417 \quad$ [cs.LG] (2017).

418 20. Lewington, S. et al. Age-specific relevance of usual blood pressure to vascular mortality: a 419 meta-analysis of individual data for one million adults in 61 prospective studies. Lancet 360, $420 \quad$ 1903-1913 (2002).

421 21. Parato, V. M. et al. Echocardiographic diagnosis of the different phenotypes of hypertrophic 422 cardiomyopathy. Cardiovasc. Ultrasound 14, 30 (2016).

423 22. Ko, W.-Y. et al. Detection of Hypertrophic Cardiomyopathy Using a Convolutional Neural 
medRxiv preprint doi: https://doi.org/10.1101/2021.06.13.21258860; this version posted June 15, 2021. The copyright holder for this preprint (which was not certified by peer review) is the author/funder, who has granted medRxiv a license to display the preprint in perpetuity.

All rights reserved. No reuse allowed without permission. 
medRxiv preprint doi: https://doi.org/10.1101/2021.06.13.21258860; this version posted June 15, 2021. The copyright holder for this preprint (which was not certified by peer review) is the author/funder, who has granted medRxiv a license to display the preprint in perpetuity.

All rights reserved. No reuse allowed without permission.

\section{FIGURES}

\section{Figure 1. LVH-Fusion study design.}

Two disease of interested are denoted, HCM and HTN, alongside data modality types used in this study. Single modal as well as multimodal model architecture were explored. LVH-Fusion is based on a late average fusion neural network, denoted in blue.

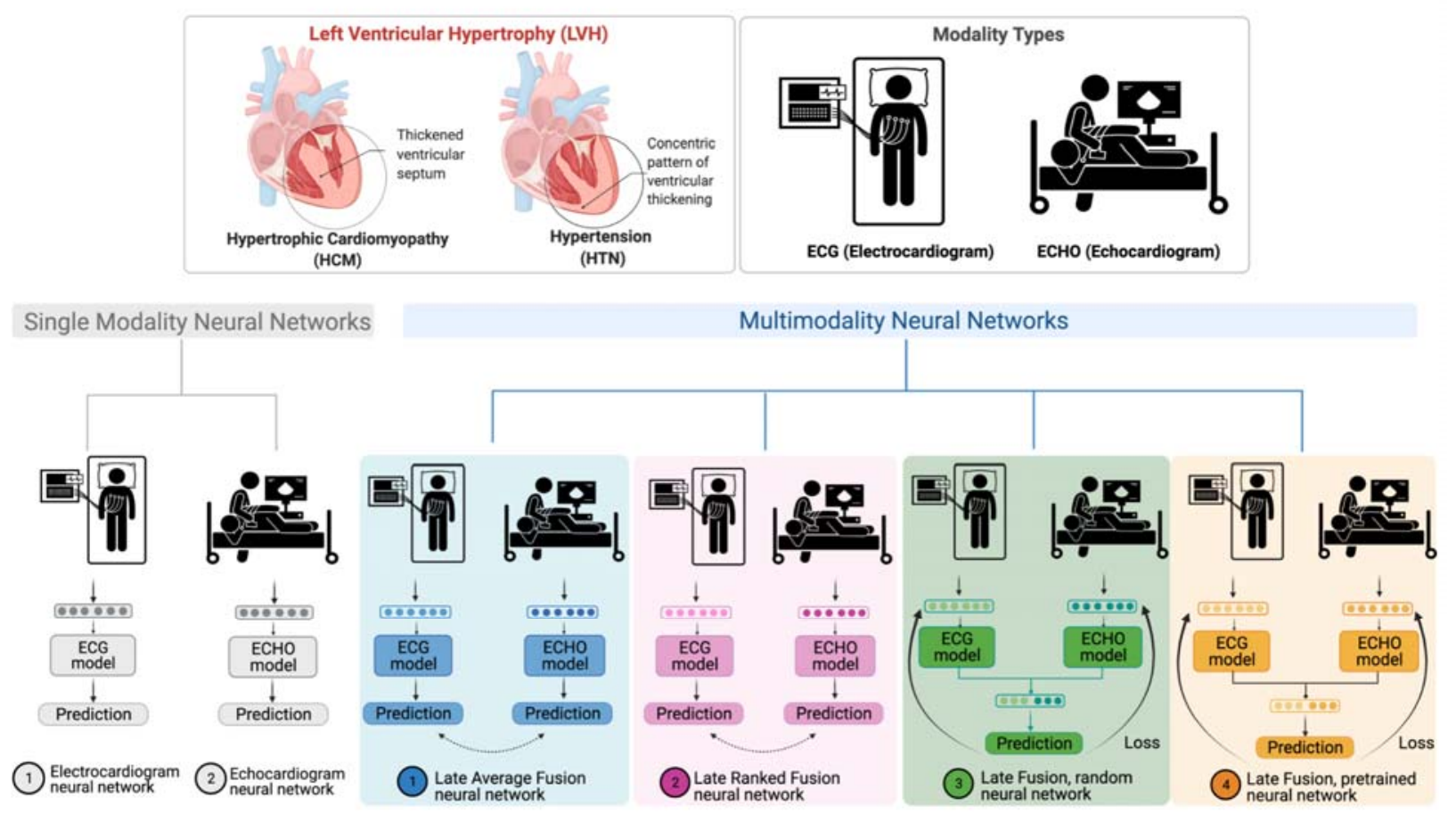

(1)


medRxiv preprint doi: https://doi.org/10.1101/2021.06.13.21258860; this version posted June 15, 2021. The copyright holder for this preprint (which was not certified by peer review) is the author/funder, who has granted medRxiv a license to display the preprint in perpetuity.

All rights reserved. No reuse allowed without permission.

Figure 2, Ablation studies impact on LVH-Fusion performance

Bootstrap 95\% CI for performance metrics, F1-score and average precision score, for each model trained on ablated input data. for each prediction metric is shown. (TOP row) Results from ablating ECG input. (BOTTOM row) Results from ablating echocardiogram input. For each ablation setting, a separate model was trained on that type of ablated data to quantify the 444 information content in the data.
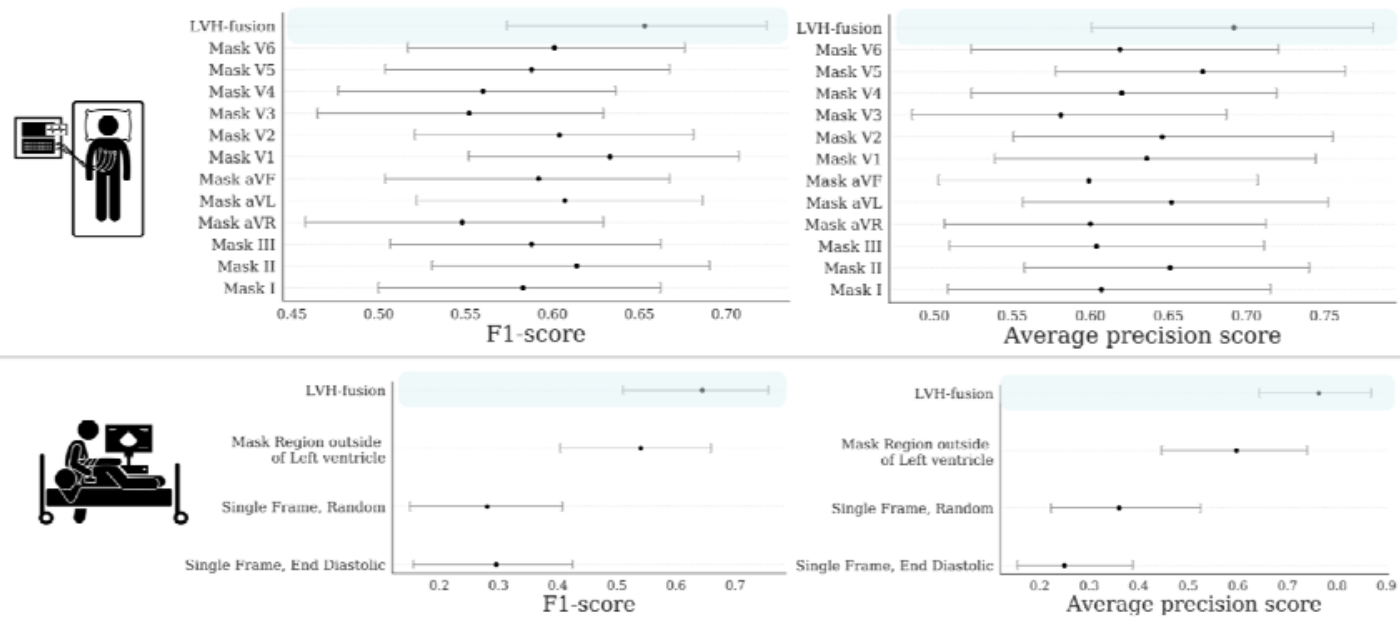
medRxiv preprint doi: https://doi.org/10.1101/2021.06.13.21258860; this version posted June 15, 2021. The copyright holder for this preprint (which was not certified by peer review) is the author/funder, who has granted medRxiv a license to display the preprint in perpetuity.

All rights reserved. No reuse allowed without permission.

\section{Figure 3, LVH-Fusion ECG interpretations.}

SHAP explanations of one true positive, HCM sample (A). Red areas indicate timesteps that hold a positive impact on prediction, while blue timesteps indicate a negative impact on prediction, no color is neutral. (B) Selected regions of ECG leads denote timesteps of high estimated importance, focusing on inverted T-waves and lead V3 R peaks. (C) Local explanations of the cumulative SHAP values on prediction output across leads. Lead V3 overall contains the highest values of SHAP values for this sample presented.

A

LVH-Fusion prediction probabilty: 77\% HCM

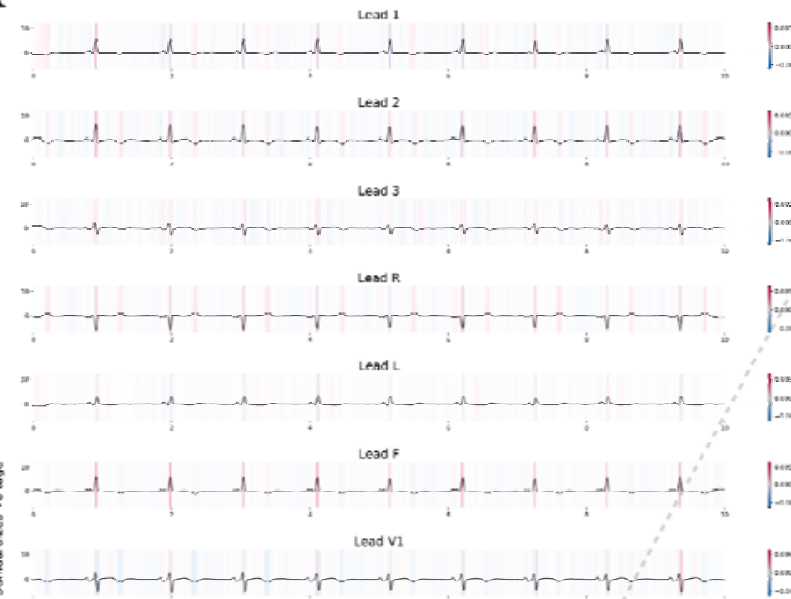

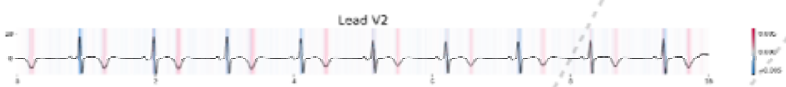
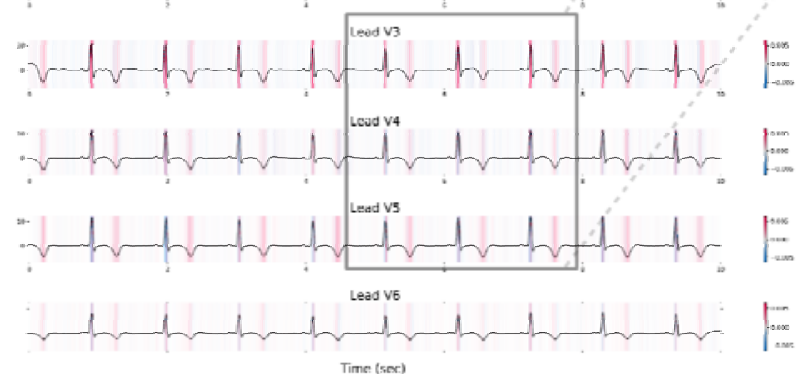

Time (ser)
B

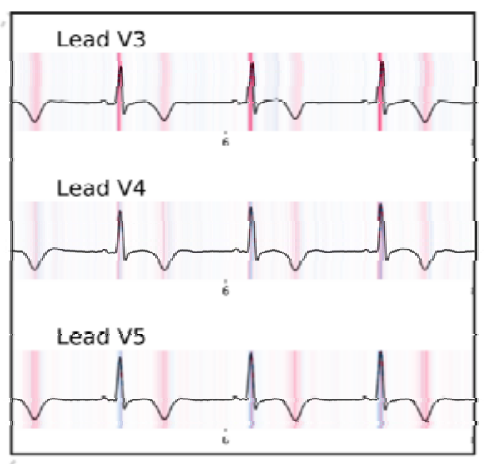

C

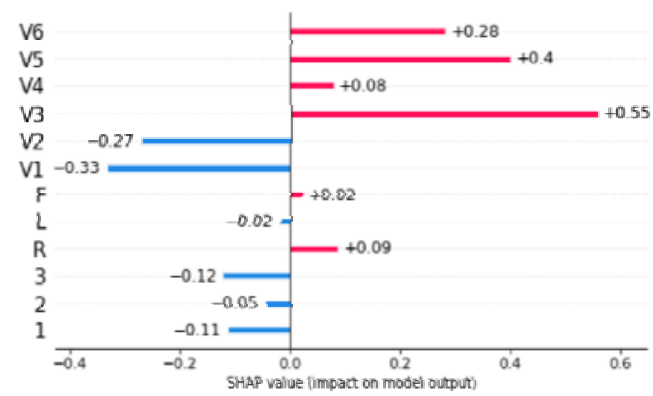


medRxiv preprint doi: https://doi.org/10.1101/2021.06.13.21258860; this version posted June 15, 2021. The copyright holder for this preprint (which was not certified by peer review) is the author/funder, who has granted medRxiv a license to display the preprint in perpetuity.

All rights reserved. No reuse allowed without permission.

460 Figure 4, LVH-Fusion echocardiogram interpretations.

461 SHAP explanations for two true positive samples, HCM (top row) and HTN (bottom row). Each 462 class has 3 frames selected with SHAP values overlaid. Red areas indicate pixels that hold a 463 positive impact on prediction, while blue pixels indicate a negative impact on prediction, no 464 color is neutral. We observe red areas of importance converging on the asymmetric septal wall in 465 the HCM example.

466

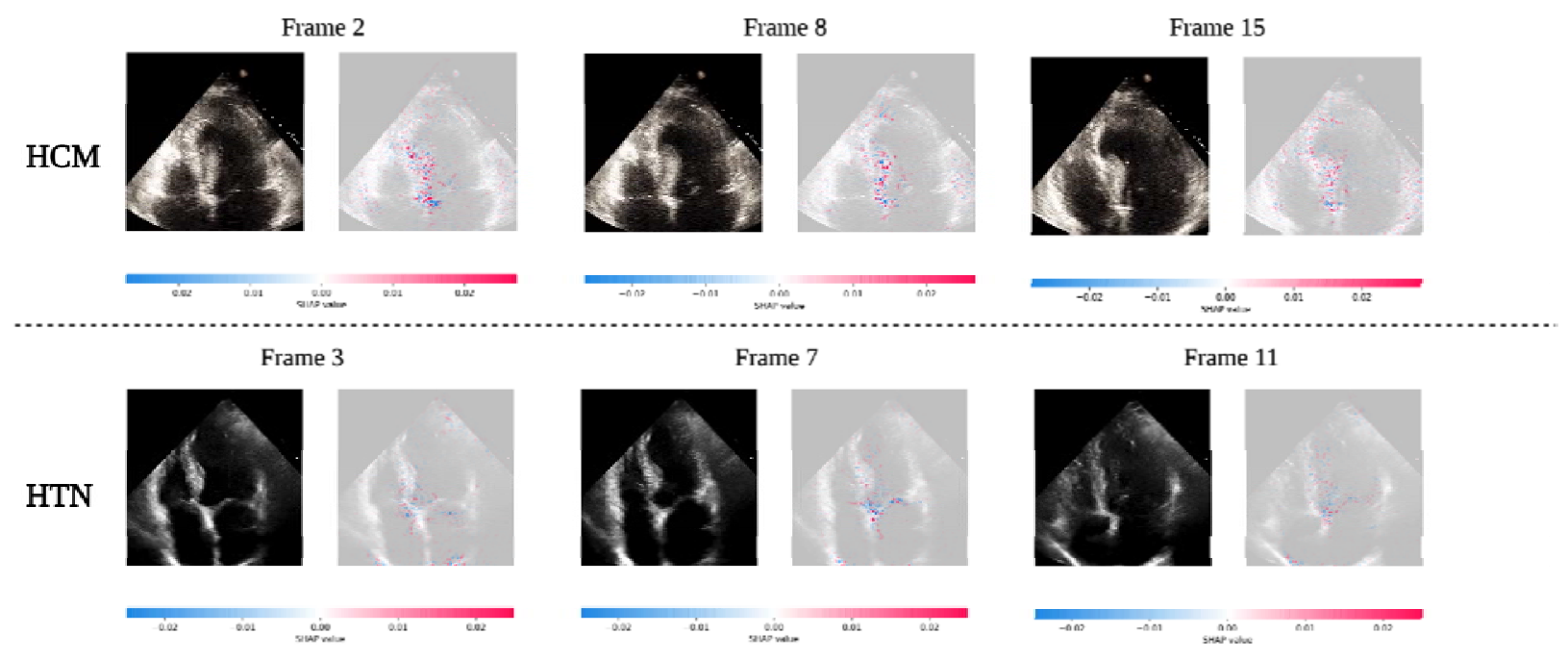


medRxiv preprint doi: https://doi.org/10.1101/2021.06.13.21258860; this version posted June 15, 2021. The copyright holder for this preprint (which was not certified by peer review) is the author/funder, who has granted medRxiv a license to display the preprint in perpetuity.

All rights reserved. No reuse allowed without permission.

470

471

TABLES

472

Table 1 Breakdown of data by partition

\begin{tabular}{|c|c|c|c|c|c|}
\hline Label & Partition & $\begin{array}{l}\text { Number of unique } \\
\text { Echo patients }\end{array}$ & $\begin{array}{l}\text { Number of } \\
\text { Echos }\end{array}$ & $\begin{array}{l}\text { Number of unique } \\
\text { ECG patients }\end{array}$ & $\begin{array}{l}\text { Number of } \\
\text { ECGs }\end{array}$ \\
\hline \multirow{3}{*}{$\mathrm{HCM}$} & Train & 256 & 596 & 662 & 4,281 \\
\hline & Validate & 31 & 58 & 71 & 424 \\
\hline & Test & 27 & 88 & 78 & 380 \\
\hline \multirow{3}{*}{ HTN } & Train & 1,469 & 1,976 & 1,535 & 8,348 \\
\hline & Validate & 186 & 270 & 191 & 1,127 \\
\hline & Test & 181 & 246 & 191 & 1,201 \\
\hline
\end{tabular}

473

474 
Table 2: Model performance metrics

\begin{tabular}{|c|c|c|c|c|c|c|c|c|c|c|}
\hline Models & auROC & auPRC & F1-score & Sensitivity & Specificity & Precision & NPV & FPR & FNR & FDR \\
\hline Late averaged fusion & $\begin{array}{l}0.914(0.858- \\
0.961)\end{array}$ & $\begin{array}{l}0.781(0.642- \\
0.898)\end{array}$ & $\begin{array}{l}0.711(0.571 \text { - } \\
0.826)\end{array}$ & $\begin{array}{l}0.727(0.560- \\
0.880)\end{array}$ & $\begin{array}{l}0.952(0.921- \\
0.979)\end{array}$ & $\begin{array}{l}0.696(0.526- \\
0.850)\end{array}$ & $\begin{array}{l}0.959(0.930- \\
0.986)\end{array}$ & $\begin{array}{l}0.048(0.021- \\
0.078)\end{array}$ & $\begin{array}{l}0.273(0.118- \\
0.438)\end{array}$ & $\begin{array}{l}0.304(0.148- \\
0.467)\end{array}$ \\
\hline Late ranked fusion & $\begin{array}{l}0.917(0.866 \text { - } \\
0.960)\end{array}$ & $\begin{array}{l}0.758(0.621 \text { - } \\
0.874)\end{array}$ & $\begin{array}{l}0.480(0.353- \\
0.591)\end{array}$ & $\begin{array}{l}0.818(0.667 \text { - } \\
0.950)\end{array}$ & $\begin{array}{l}0.760(0.701- \\
0.818)\end{array}$ & $\begin{array}{l}0.340(0.235- \\
0.449)\end{array}$ & $\begin{array}{l}0.965(0.935 \text { - } \\
0.991)\end{array}$ & $\begin{array}{l}0.240(0.182 \text { - } \\
0.299)\end{array}$ & $\begin{array}{l}0.182(0.050- \\
0.333)\end{array}$ & $\begin{array}{l}0.660(0.552- \\
0.766)\end{array}$ \\
\hline Late fusion random & $\begin{array}{l}0.890(0.832 \text { - } \\
0.941)\end{array}$ & $\begin{array}{l}0.643(0.475- \\
0.803)\end{array}$ & $\begin{array}{l}0.556(0.409- \\
0.681)\end{array}$ & $\begin{array}{l}0.682(0.500- \\
0.842)\end{array}$ & $\begin{array}{l}0.884(0.838- \\
0.925)\end{array}$ & $\begin{array}{l}0.469(0.323- \\
0.621)\end{array}$ & $\begin{array}{l}0.949(0.915- \\
0.978)\end{array}$ & $\begin{array}{l}0.116(0.075- \\
0.162)\end{array}$ & $\begin{array}{l}0.318(0.156- \\
0.500)\end{array}$ & $\begin{array}{l}0.531(0.382 \text { - } \\
0.679)\end{array}$ \\
\hline Late fusion pretrained & $\begin{array}{l}0.891(0.829- \\
0.943)\end{array}$ & $\begin{array}{l}0.625(0.460- \\
0.784)\end{array}$ & $\begin{array}{l}0.452(0.333- \\
0.556)\end{array}$ & $\begin{array}{l}0.864(0.731- \\
0.967)\end{array}$ & $\begin{array}{l}0.705(0.642- \\
0.767)\end{array}$ & $\begin{array}{l}0.306(0.210- \\
0.403)\end{array}$ & $\begin{array}{l}0.972(0.943- \\
1.000)\end{array}$ & $\begin{array}{l}0.295(0.234- \\
0.359)\end{array}$ & $\begin{array}{l}0.136(0.033- \\
0.269)\end{array}$ & $\begin{array}{l}0.694(0.596- \\
0.787)\end{array}$ \\
\hline Single modal: ECG & $\begin{array}{l}0.834(0.784- \\
0.880)\end{array}$ & $\begin{array}{l}0.686(0.590- \\
0.776)\end{array}$ & $\begin{array}{l}0.639(0.555- \\
0.712)\end{array}$ & $\begin{array}{l}0.676(0.580- \\
0.770)\end{array}$ & $\begin{array}{l}0.831(0.786- \\
0.877)\end{array}$ & $\begin{array}{l}0.605(0.512- \\
0.696)\end{array}$ & $\begin{array}{l}0.871(0.828- \\
0.912)\end{array}$ & $\begin{array}{l}0.169(0.123- \\
0.216)\end{array}$ & $\begin{array}{l}0.324(0.231- \\
0.418)\end{array}$ & $\begin{array}{l}0.395(0.304- \\
0.488)\end{array}$ \\
\hline $\begin{array}{l}\text { Single modal: } \\
\text { Echocardiogram }\end{array}$ & $\begin{array}{l}0.889(0.828- \\
0.942)\end{array}$ & $\begin{array}{l}0.719(0.588- \\
0.833)\end{array}$ & $\begin{array}{l}0.625(0.500- \\
0.735)\end{array}$ & $\begin{array}{l}0.741(0.591- \\
0.875)\end{array}$ & $\begin{array}{l}0.906(0.870- \\
0.940)\end{array}$ & $\begin{array}{l}0.541(0.406- \\
0.676)\end{array}$ & $\begin{array}{l}0.959(0.932- \\
0.982)\end{array}$ & $\begin{array}{l}0.094(0.060 \text { - } \\
0.130)\end{array}$ & $\begin{array}{l}0.259(0.125- \\
0.407)\end{array}$ & $\begin{array}{l}0.459(0.324- \\
0.595)\end{array}$ \\
\hline
\end{tabular}


medRxiv preprint doi: https://doi.org/10.1101/2021.06.13.21258860; this version posted June 15, 2021. The copyright holder for this preprint (which was not certified by peer review) is the author/funder, who has granted medRxiv a license to display the preprint in perpetuity.

All rights reserved. No reuse allowed without permission.

\section{SUPPLEMENTAL TABLES AND FIGURES}

478

479

\section{Supplemental Table S1}

\begin{tabular}{|c|c|c|c|c|c|}
\hline Data Selection & Label & Number of unique Echo patients & Number of Echos & Number of unique ECG patients & Number of ECGs \\
\hline \multirow{4}{*}{ First Encounters, train, val, and test } & $\mathrm{HCM}$ & & & & \\
\hline & & 314 & 314 & 811 & 811 \\
\hline & HTN & & & & \\
\hline & & 1,836 & 1,836 & 1,917 & 1,917 \\
\hline \multirow[t]{4}{*}{ First Encounter, val and test } & $\mathrm{HCM}$ & & & & \\
\hline & & 314 & 654 & 811 & 4,430 \\
\hline & HTN & & & & \\
\hline & & 1,836 & 2,343 & 1,917 & 8,730 \\
\hline \multirow[t]{4}{*}{ All Encounters train, val, and test } & $\mathrm{HCM}$ & & & & \\
\hline & & 324 & 763 & 917 & 6,027 \\
\hline & HTN & & & & \\
\hline & & 1,848 & 2,516 & 1,977 & 13,045 \\
\hline
\end{tabular}


medRxiv preprint doi: https://doi.org/10.1101/2021.06.13.21258860; this version posted June 15, 2021. The copyright holder for this preprint (which was not certified by peer review) is the author/funder, who has granted medRxiv a license to display the preprint in perpetuity.

All rights reserved. No reuse allowed without permission.

Supplemental Table S2

\begin{tabular}{|c|c|c|c|c|c|}
\hline Model & Loss & auPRC & Optim & Batch & Data Selection \\
\hline VGG11 & 0.502 & 0.591 & adam & 75 & First Encounters, all \\
\hline VGG13 & 0.448 & 0.672 & adam & 64 & First Encounters, all \\
\hline VGG16 & 0.493 & 0.559 & adam & 64 & First Encounters, all \\
\hline VGG19 & 0.501 & 0.559 & adam & 64 & First Encounters, all \\
\hline densenet 121 & 0.395 & 0.738 & adam & 64 & First Encounters, all \\
\hline densenet161 & 0.449 & 0.639 & adam & 64 & First Encounters, all \\
\hline densenet 169 & 0.41 & 0.722 & adam & 75 & First Encounters, val and test only \\
\hline densenet 201 & 0.433 & 0.724 & adam & 64 & First Encounters, all \\
\hline resnet101 & 0.427 & 0.702 & adam & 75 & First Encounters, all \\
\hline resnet 152 & 0.434 & 0.715 & adam & 64 & First Encounters, all \\
\hline resnet18 & 0.405 & 0.727 & adam & 64 & First Encounters, all \\
\hline resnet34 & 0.383 & 0.781 & adam & 64 & First Encounters, all \\
\hline resnet50 & 0.429 & 0.73 & adam & 75 & First Encounters, all \\
\hline resnext101_32x8d & 0.405 & 0.741 & adam & 75 & First Encounters, all \\
\hline resnext50_32x4d & 0.405 & 0.734 & adam & 64 & First Encounters, all \\
\hline wide_resnet101_2 & 0.426 & 0.69 & adam & 75 & First Encounters, all \\
\hline wide_resnet50_2 & 0.416 & 0.692 & adam & 64 & First Encounters, all \\
\hline
\end{tabular}

483 
medRxiv preprint doi: https://doi.org/10.1101/2021.06.13.21258860; this version posted June 15, 2021. The copyright holder for this preprint (which was not certified by peer review) is the author/funder, who has granted medRxiv a license to display the preprint in perpetuity.

All rights reserved. No reuse allowed without permission.

485

Supplemental Table S3

\begin{tabular}{ccccccc}
\hline Model & loss & auPRC & optim & frames & period & File selection \\
mc3 & 0.134 & 0.893 & adam & 16 & 2 & First Encounters, all \\
r2plus1d & 0.171 & 0.851 & adam & 16 & 4 & First Encounters, all \\
r3d & 0.152 & 0.879 & adam & 16 & 4 & First Encounters, all
\end{tabular}

486

Supplemental Table S4

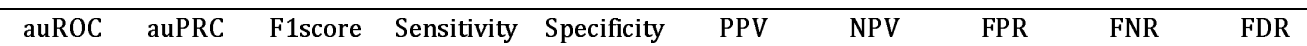

Reduced features (11)

$\begin{array}{llllllllll}0.71 & 0.59 & 0.5 & 0.43 & 0.89 & 0.6 & 0.8 & 0.11 & 0.57 & 0.4\end{array}$

Large features (468)

487

488 
medRxiv preprint doi: https://doi.org/10.1101/2021.06.13.21258860; this version posted June 15, 2021. The copyright holder for this preprint (which was not certified by peer review) is the author/funder, who has granted medRxiv a license to display the preprint in perpetuity.

All rights reserved. No reuse allowed without permission.

Supplemental Table S5

\begin{tabular}{ccccc}
\hline & f1-score & precision & recall & support \\
\hline HTN & & & & \\
HCM & 0.71 & 0.78 & 0.65 & 181 \\
NORMAL EF & 0.41 & 1.00 & 0.26 & 27 \\
& 0.95 & 0.92 & 0.97 & 876 \\
\hline macro avg & & & & \\
weighted avg & 0.69 & 0.90 & 0.63 & 1084 \\
& 0.89 & 0.90 & 0.90 & 1084 \\
\hline & & & & \\
\hline
\end{tabular}

Supplemental Table S6

\begin{tabular}{lcccc}
\hline & f1-score & precision & recall & support \\
\hline HTN & 0.39 & 0.35 & 0.44 & 178 \\
HCM & 0.36 & 0.26 & 0.57 & 68 \\
SINUS & 0.91 & 0.95 & 0.88 & 1789 \\
& & & & \\
& & & & \\
macro avg & 0.56 & 0.52 & 0.63 & 2035 \\
weighted avg & 0.85 & 0.87 & 0.83 & 2035 \\
& & & & \\
\hline
\end{tabular}

494

495 


\section{Supplemental Figure S1, Additional examples of true positive HCM ECGs}

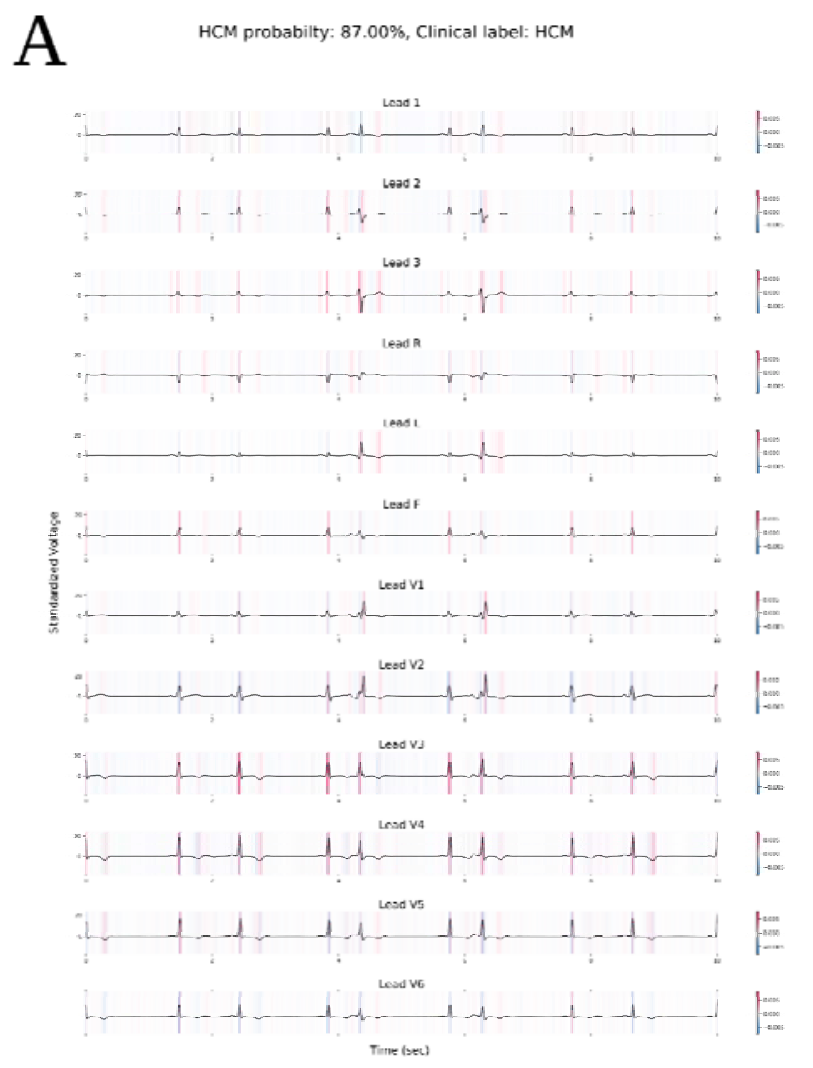

B HCM probabilty: $96.00 \%$, Clinical label: HCM

500

501 
medRxiv preprint doi: https://doi.org/10.1101/2021.06.13.21258860; this version posted June 15, 2021. The copyright holder for this preprint (which was not certified by peer review) is the author/funder, who has granted medRxiv a license to display the preprint in perpetuity.

All rights reserved. No reuse allowed without permission.
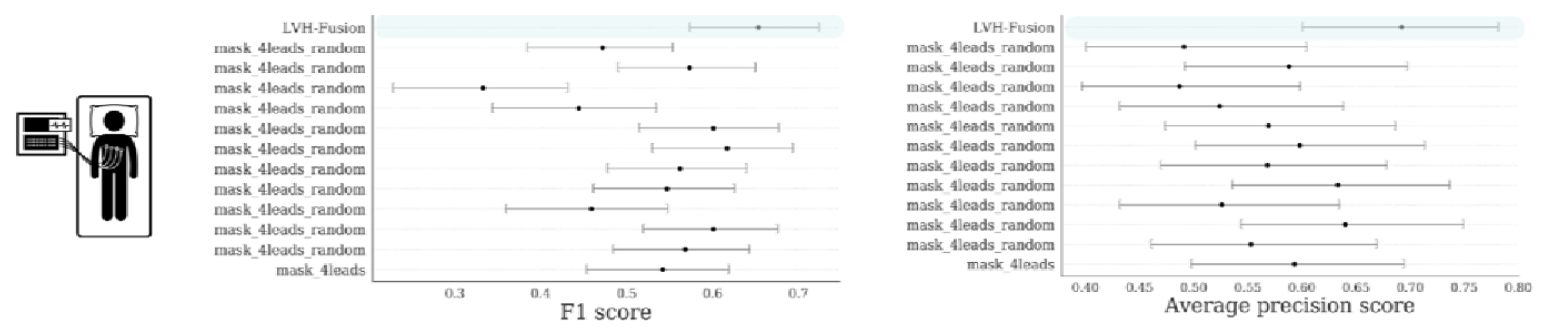

\section{Supplemental Figure S3, Echo SHAP local feature importance plot}

A
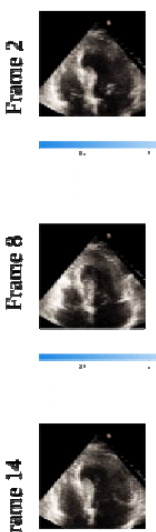

HCM

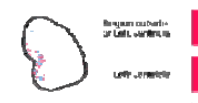

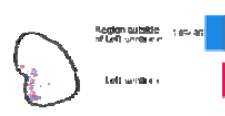

C un want.
B
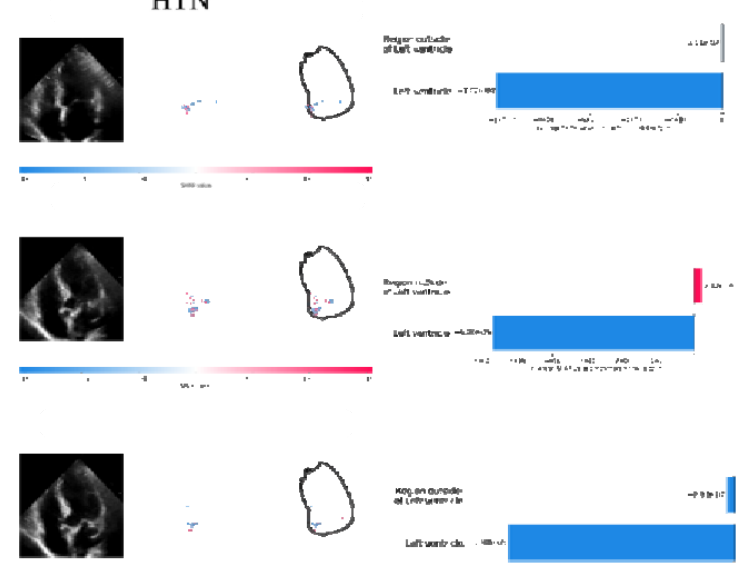

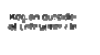

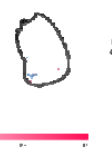


medRxiv preprint doi: https://doi.org/10.1101/2021.06.13.21258860; this version posted June 15, 2021. The copyright holder for this preprint (which was not certified by peer review) is the author/funder, who has granted medRxiv a license to display the preprint in perpetuity.

All rights reserved. No reuse allowed without permission.

\section{Supplemental Figure S4, ECG SHAP global feature importance plot}

509 The global importance of each lead is taken to be the mean absolute value summation for each

510 lead over all the given samples. Hypertension (HTN) is in solid red, Hypertrophic

511 Cardiomyopathy (HCM) is denoted by stripes. Lead V3 is ranks highest overall in global feature

512 importance.

513

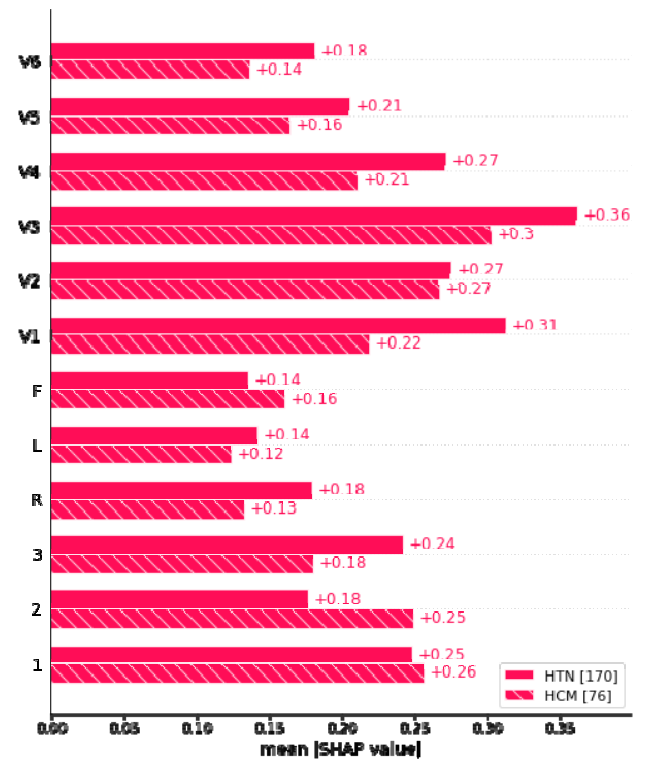

